\title{
Hypertrophic osteoarthropathy as the cause of situs inversus totalis: A case report
}

\author{
Esteban Grandy ${ }^{1}$, Giuseppe Grandy ${ }^{2 *}$ \\ ${ }^{1}$ Departamento de Medicina Interna, Hospital Obrero, Centro de Pediatria Albina Pati, Cochabamba, Bolivia \\ ${ }^{2}$ Pediatric Center Albina Patino, Instituto de Nutrición y Tecnología de los Alimentos, Macul, Santiago, Chile \\ Email: egrandy@hotmail.es, "ggrandy@inta.cl
}

Received 23 March 2012; revised 29 April 2012; accepted 14 May 2012

\begin{abstract}
Situs inversus totalis is a very rare anomaly. Even more, cases of situs inversus totalis plus hypertrophic osteoarthropathy. A woman presented with cyanosis, clubbing of fingers and distal edema. Chest examination revealed heart sounds at the right side and a heart murmur. Abdominal examination showed liver dullness in the left side. The $\mathrm{X}$-rays showed dextrocardia and liver in the left side. The Upper digestive barium test showed the stomach in the right side, the barium enema showed caecum on the left. Treatment for heart failure improved the patient's condition and she remained well. When she became pregnant, developed heart failure again and required admission. She was compensated and continued her pregnancy. 3 years later she developed heart and respiratory refractory failure, was admitted again and after few days she died. We report this case of situs inversus totalis in association with hypertrophic osteoarthropathy because of the rarity of this anomaly.
\end{abstract}

Keywords: Situs Inversus Totalis; Hypertrphic Osterathropathy

\section{INTRODUCTION}

Situs inversus totalis is a congenital anomaly occurring in 1 in 10,000 - 50,000 live births [1]; the condition is defined by a complete mirror image of the thoracic and abdominal viscera. Affected patients may appear healthy, with no differences in their life expectancy. In some cases patients present additional hearth anomalies, such as interatrial communication.

The systematic search of the literature did not disclose cases of situs inversus totalis plus hypertrophic osteoarthropathy. This case probably is the first report. In view of this, we herewith present this case.

\footnotetext{
"Corresponding author.
}

\section{CASE PRESENTATION}

A merchant, native ethnicity, 22-year-old woman was referred as outpatient to our hospital for assessment of her heart condition. She had a long-lasting history, around 10 years, of increased volume in up and lower limbs with intermittent pain, cyanosis, clubbing of fingers and toes, distal edema and fatigue. Prior history did not disclose features suggesting malnutrition, diabetes, hypertension, abdominal surgery or trauma or chronic medication. The patient neither smoked nor ingested alcoholic beverages. On physical examination, body temperature was $37^{\circ} \mathrm{C}$, pulse rate $78 \mathrm{bpm}$ and blood pressure 120/80 mm Hg. There was intense peripheral cyanosis; the apex beat was in the right fifth intercostals space, midclavicular line. Heart sounds were abnormal, with a holosystolic murmur (grade 4/4). Examination of the respiratory system did not reveal abnormal, in the abdomen liver dullness was on the left side. There was pitting edema especially at the lower extremities, which were also noted to be remarkably large. Clubbing of the fingers was evident in all limbs (Figure 1).

The laboratory findings were: hematocrit of $45 \%$, hemoglobin of $14 \mathrm{~g} / \mathrm{dl}$, white blood cells of $8500 / \mathrm{mm}^{3}$, blood urea of $12 \mathrm{mg} / \mathrm{dL}$, creatinine of $0.7 \mathrm{mg} / \mathrm{dL}$ and urine examination was normal.

Other findings were: Dextrocardia and cardiomegaly seen on chest X-ray (Figure 2(a)), dextrocardia interventricular communication, and complete atrioventricular canal on electrocardiography (Figure 2(b)). X-ray of the forearm, and tibia revealed extensive subperiosteal bone appositions compatible with generalized hypertrophic osteoarthropathy (Figure 3). The abdominal X-ray showed hepatomegaly and the liver in the left side. Upper digestive barium test showed the stomach in the right side and the barium enema showed caecum on the left side (Figure 4).

Based in the clinic and imagenology diagnostic, we initiated treatment with furosemide, enalaprile and digoxine to control the heart failure; joints pain was attenuated by ibuprofen. The patient became stabilized and 


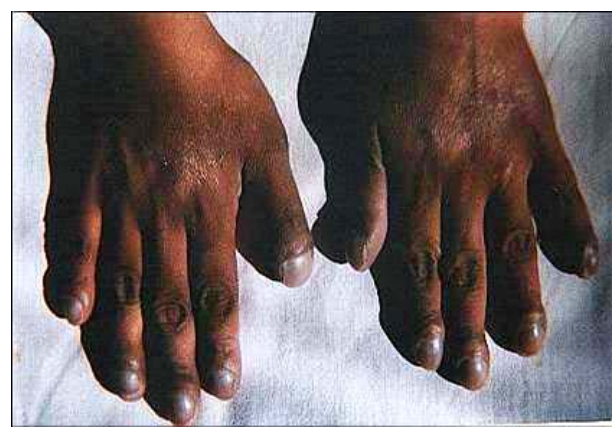

(a)

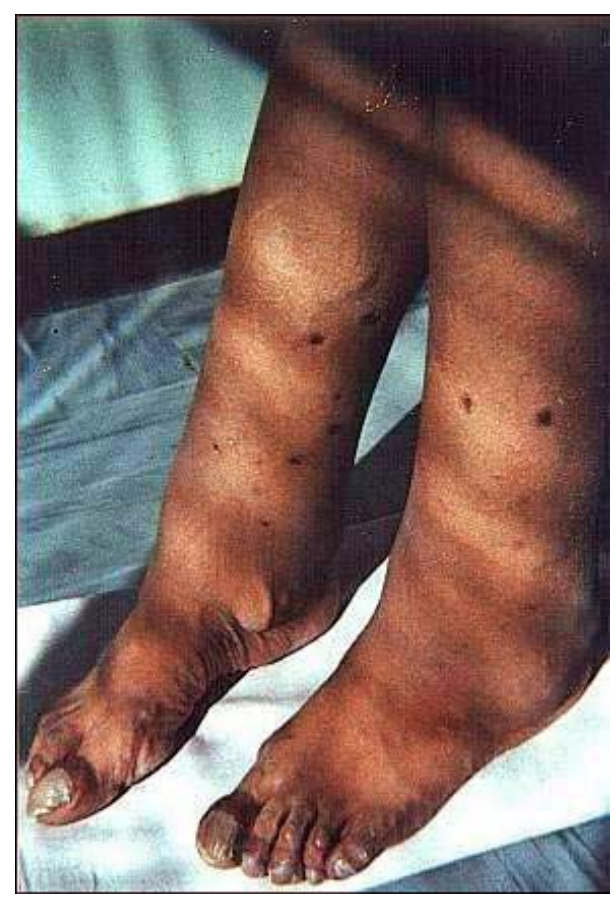

(b)

Figure 1. (a) Illustrates intense finger clubbing in both hands; (b) Show finger clubbing and edematous swelling in both lower limbs, at moment of the diagnosis.

after a few days she was discharged, remaining well and periodically controlled as outpatient.

Four year later the patient became pregnant, she was controlled more frequently, remaining stabilized until the second trimester of pregnancy, when presented heart failure again and was admitted again for treatment. After 33 weeks gestation she delivered a healthy female newborn by cesarean section, without complications. The patient continued her daily life uneventfully, with periodical medical controls; 3 years later and without new events taking place, she developed heart failure again that did not respond to treatment and died a few days later.

At all times the possibilities of treatment were limited due to the poor economic conditions of the patient's

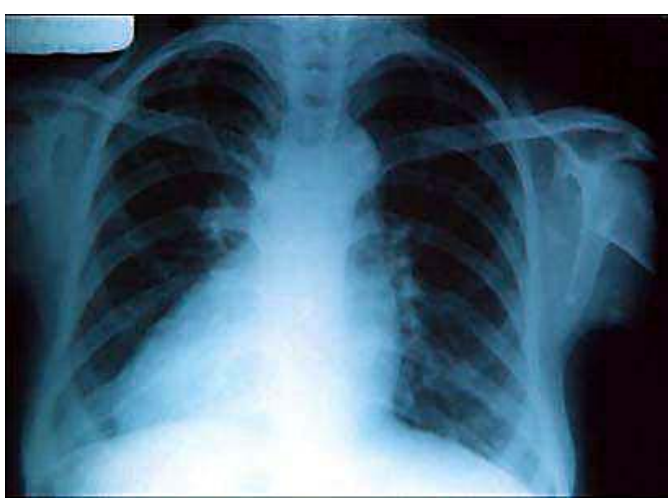

(a)

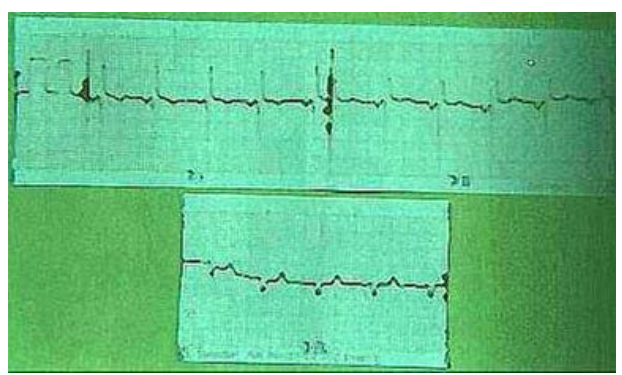

(b)

Figure 2. (a) Chest X-ray showing dextrocardia and cardiomegaly; (b) The electrocardiography reveals dextrocardia, at moment of the diagnosis.

family, who could not afford surgical or other options.

\section{DISCUSSION}

Occasionally some humans (1/10,000 - 500,000 live births) have a congenital anomaly call situs inversus [2]. The term "situs" refers to the position of the heart and viscera relative to midline. Situs solitus represents the normal position of the heart and abdominal viscera, with the cardiac apex, spleen, stomach, and aorta located on the left and the liver and inferior vena cava located on the right. Situs inversus totalis or situs inversus with dextrocardia indicates mirror-image location of the heart and viscera relative to situs solitus. This congenital heart disease occurs in $3 \%-5 \%$ of cases [3,4]. Some times the dextrocardia is accompanied with others cardiac anomalies like interventricular communication, interatrial communication, complete atrioventricular canal [5].

Pierre-Marie-Bamberger syndrome or else hypertrophic pulmonary osteoarthropathy (HPOA) constitutes a clinical syndrome characterized by clubbing of fingers and toes, arthritis and periostosis of the long distal bones. The lesions are usually bilateral and symmetric causing swelling and extreme pain of the affected limbs. It may occur as a primary condition, which is familial and affects mainly males [6], but most of the times is the manifestation of other conditions characterized by arte 


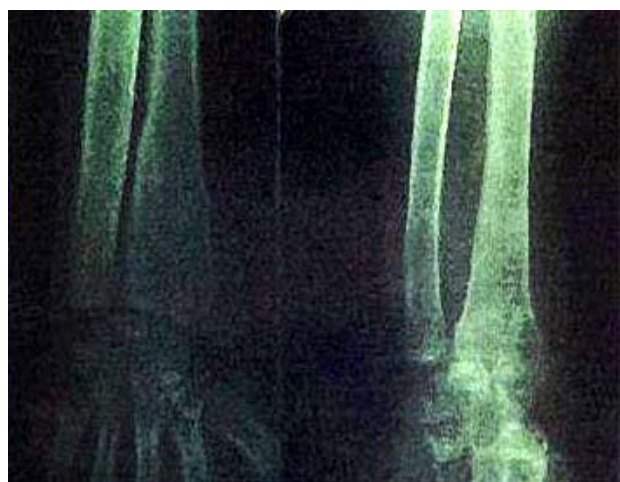

(a)

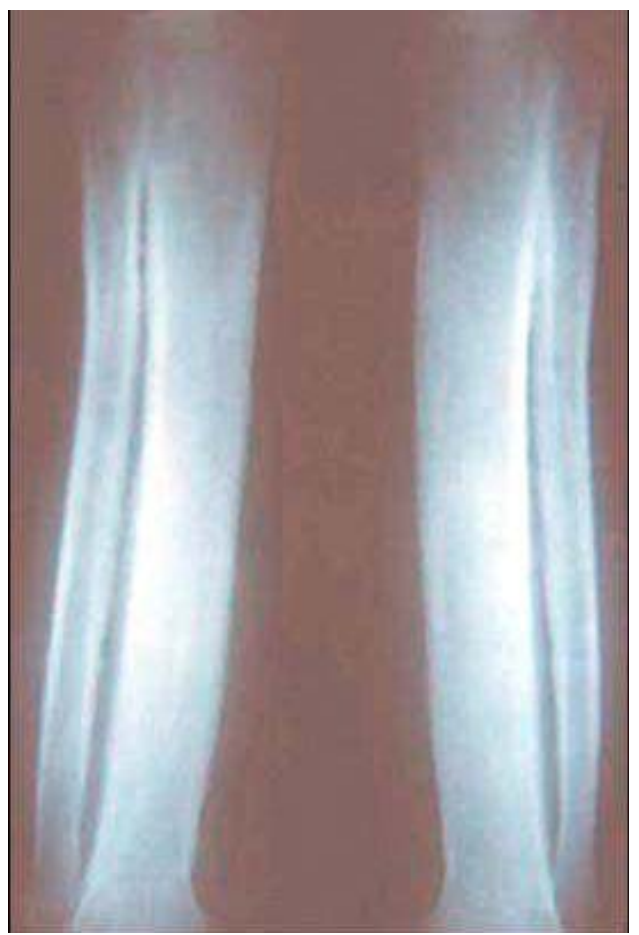

(b)

Figure 3. (a) X-ray of the forearm showing characteristic periosteal bone apposition; (b) X-ray of the tibia showing characteristic periosteal bone apposition, at moment of the diagnosis.

riovenous shunt like lung carcinoma, mesothelioma, pulmonary tuberculosis, congenital cyanotic heart disease, hepatic and colorectal carcinoma, inflammatory bowel disease, cirrhosis, pulmonary fibrosis and empyema [7, 8].

We didn't had the surgical option in order to treat the congenital heart diseases, first because the patient and her family didn't had the economic sufficiency to pay this kind to surgery, secondly the capacity to treat and controlled this kind of cases probably is limited in Bolivia.

The medical treatment only attenuate the symptoms, but not was the cure, but we tried to give her the best

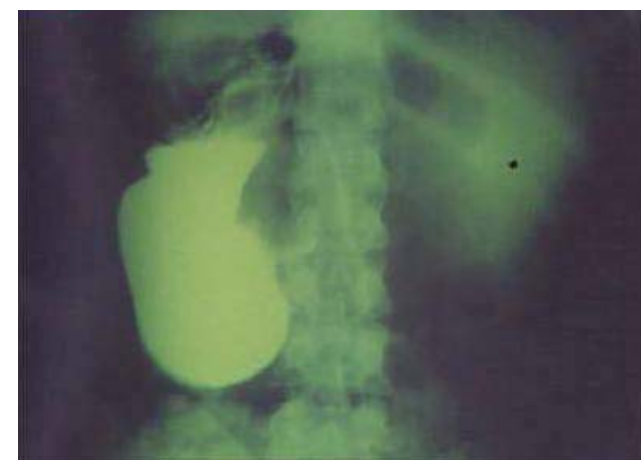

(a)

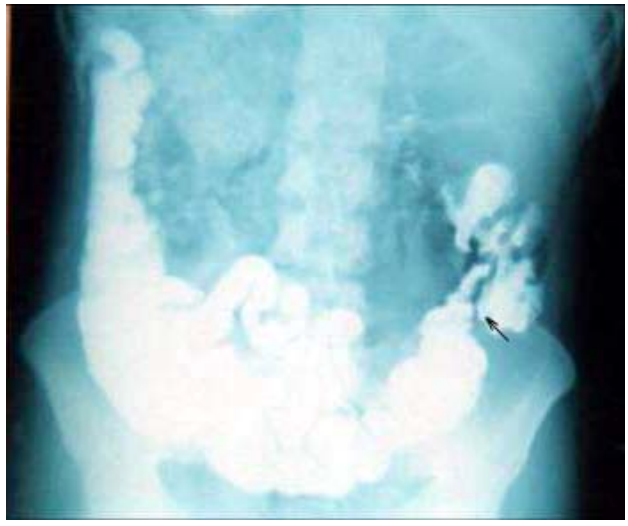

(b)

Figure 4. (a) Upper digestive barium test showed the stomach in the right and the liver in the left side; (b) Barium enema showed the caecum (arrow) on the left side, at moment of the diagnosis.

quality of life, even more she can had a baby in this situation.

\section{CONCLUSION}

This case of situs inversus totalis is very rare, furthermore if we thing in the other multiples hearth abnormalities she had and the kind of presentation as HPOA. As far as known it probably is the first case report, at least in Bolivia.

\section{REFERENCES}

[1] Murakami, S., Terakado, M., Misumi, M., Tsuji, Y., Okudo, K., Hirayama, R., Inoue, K. and Arai, E. (2003) Situs inversus totalis with malignant lymphoma of the stomach: Report of case. Surgery Today, 33, 533-566.

[2] Aylsworth, A.S. (2001) Clinical aspects of defects in the determination of laterality. American Journal of Medical Genetics, 101, 345-355. doi:10.1002/ajmg.1219

[3] Fulcher, A. and Turner, M.A. (2002) Abdominal manifestations of situs anomalies in adults. Radiographics, 22, 1439-1456.

[4] Benjelloun, E.B., Zahid, F., Ousadden, A., Mazaz, K. and 
Taleb, K.A. (2008) A case of gastric cancer associated to situs inversus totalis. Cases Journal, 12, 1.

[5] Carvalho, J.S. and Kyle, U.K. (1997) Images in cardiovascular medicine. Situs inversus with complete transposition in the fetus: Diagnostic antenatal sequential segmental analysis. Circulation, 96, 4432-4433. doi:10.1161/01.CIR.96.12.4432

[6] Karkuca, M., Erturk, E., Capkin, E., Akyazi, H., Ozden, G. and Tosun, M. (2007) Primary hypertrophic osteoarthropathy (pachydermoperiostosis): A case report. Rheumatology International, 27, 403-405.

doi:10.1007/s00296-006-0216-2
[7] Armstrong, D., McCausland, E. and Wright. G. (2007) Hypertrophic pulmonary osteoarthropathy (HPOA) (Pierre Marie-Bamberger syndrome): Two cases presenting as acute inflammatory arthritis. Description and review of the literature. Rheumatology International, 27, 399-402. doi:10.1007/s00296-006-0224-2

[8] Ntaios, G., Adamidou, A. and Karamitsos, D. (2008) Hipertrophic pulmonary osteoarthropathy secondary to bronchial adenocarcinoma and coexisting pulmonary tuberculosis: A case report. Cases Journal, 1, 221. doi:10.1186/1757-1626-1-221 